\title{
Wear and Corrosion Resistance of Chromium-Vanadium Carbide Coatings Produced via Thermo-Reactive Deposition
}

\author{
Fabio Castillejo ${ }^{1}$, Jhon Jairo Olaya ${ }^{2, *}$ and Jose Edgar Alfonso ${ }^{3}$ \\ 1 Grupo de Ciencia e Ingeniería de Materiales, Universidad Santo Tomás, Carrera 9 No 51-11, \\ Bogotá 110911, Colombia; fabiocastillejo@usantotomas.edu.co \\ 2 Departamento de Ingeniería Mecánica y Mecatrónica, Universidad Nacional de Colombia, \\ Carrera 45 No 26-85, Bogotá 110911, Colombia \\ 3 Departamento de Física, Universidad Nacional de Colombia, Carrera 45 No 26-85, Bogotá 110911, Colombia; \\ jealfonsoo@unal.edu.co \\ * Correspondence: jjolayaf@unal.edu.co
}

Received: 15 February 2019; Accepted: 20 March 2019; Published: 27 March 2019

\begin{abstract}
Chromium carbide, vanadium carbide, and chromium-vanadium mixture coatings were deposited on AISI D2 steel via the thermo-reactive deposition/diffusion (TRD) technique. The carbides were obtained from a salt bath composed of molten borax, ferro-chrome, ferro-vanadium, and aluminum at $1020^{\circ} \mathrm{C}$ for $4 \mathrm{~h}$. Analysis of the morphology and microstructure of the coatings was done via scanning electron microscopy (SEM) and X-ray diffraction (XRD), respectively. The hardness of the coatings was evaluated using nano-indentation, and the friction coefficient was determined via pin-on-disk (POD) testing. The electrochemical behavior was studied through potentiodynamic polarization tests and electrochemical impedance spectroscopy (EIS). The XRD results show evidence of the presence of $\mathrm{V} 8 \mathrm{C} 7$ in the vanadium carbide coating and $\mathrm{Cr} 23 \mathrm{C} 6$ and $\mathrm{Cr} 7 \mathrm{C} 3$ in the chromium carbide coating. The hardness value for the vanadium-chromium carbide coating was $23 \mathrm{GPa}$, which was higher than the $6.70 \pm 0.28 \mathrm{GPa}$ for the uncoated steel. The wear and corrosion resistance obtained was higher for the niobium-chromium carbide coating, due to the nature of the ceramic carbide produced.
\end{abstract}

Keywords: carbides; chromium; corrosion; TRD diffusion; vanadium; wear

\section{Introduction}

AISI D2 steel is widely used in the manufacturing industry, especially in the development of dies, due to its high degree of hardness and wear resistance. However, the tribological and wear resistance performance of tool steels can be enhanced by the application of surface treatments that allow coatings of carbides or nitrides of transition metals to be obtained, which help to improve the tribological and chemical properties of materials that work under conditions of high wear or corrosion, such as the materials for forming dies and cutting tools, which function in aggressive environments such as coastal cities. The coatings are industrially produced using techniques such as physical vapor phase deposition (PVD) and chemical vapor deposition (CVD) [1,2]. In general, these processes are mainly limited to equipment to be used for operation in a high vacuum, making them very expensive to install and put into production at the industrial level. An alternative for producing hard coatings with good wear resistance is the thermo-reactive deposition/diffusion (TRD) process [3], which is applied over substrates containing a higher percentage of carbon, up to $0.3 \%$ by weight [4]. Coatings produced using this process have good adhesion to the substrate, a low friction coefficient, and excellent thickness uniformity $[4,5]$. In this coating process, a bath of molten salts can be used, consisting of borax, 
aluminum, or ferro-silicon as the reducing element and carbide-forming elements (FCEs) such as vanadium, chromium, titanium, and niobium [4]. The carbide layer growth is produced when the metal dissolved in the salt bath has a relatively low energy of formation of carbide and an energy of formation of the metal oxide greater than that of boron oxide $\left(\mathrm{B}_{2} \mathrm{O}_{3}\right)$. If this condition is not met $[6,7]$, the boron atoms do not rust and are free to diffuse into the matrix of the steel, combining with the iron to form layers of iron oxide ( $\mathrm{FeO}$ and $\left.\mathrm{Fe}_{2} \mathrm{~B}\right)[8,9]$.

Papers published to date have studied binary metal carbides deposited via the TRD process and have characterized their microstructure, wear resistance, and mechanical behavior. Additionally, they have focused on the production of $\mathrm{VC}, \mathrm{CrC}$, and $\mathrm{NbC}$ coatings on substrates of AISI H13, AISI M2, and AISI D2 steel, and up to $2300 \mathrm{HV}$ hardness has been reported [3,5]. Others researchers have studied the layer growth kinetics of niobium carbides, borides, and chromium [10-12]. With respect to the electrochemical behavior of the coatings, there are papers on chromium carbides in which the relation between the microstructure and the corrosion resistance was studied using potentiodynamic polarization, as well as impedance studies (EIS) [13]. Furthermore, studies have been conducted on the corrosion and mechanical properties of nano-vanadium carbide coatings deposited via sputtering on tool steels, showing better mechanical performance for the coating-substrate combination than that exhibited by the substrate [14]. Further investigations have been made on the electrochemical behavior of nano-coatings of chromium carbide alloys deposited on Ti6Al4V and $\mathrm{Co}-\mathrm{Cr}-\mathrm{Mo}$ [15] and on the resistance to the corrosion and wear of niobium-chromium carbides deposited on tool steels. However, there have been no reports of studies on the corrosion and wear resistance of vanadium carbide and chromium carbide systems. Therefore, the objective of this paper is to deposit these coatings on D2 steel substrates using the TRD technique with the aim of combining the properties of the high degree of hardness of vanadium carbide and the good corrosion resistance of chromium carbide. The coatings produced are characterized and compared with the performance of binary carbides and chromium carbides with respect to their mechanical and electrochemical behavior.

\section{Materials and Methods}

Coatings of vanadium carbide, chromium carbide, and chromium-vanadium carbide were deposited on substrates of AISI D2 steel with dimensions of $15 \mathrm{~mm}$ in diameter and $4 \mathrm{~mm}$ in thickness, polished using emery paper of 220 to 1200, and subjected to ultrasonic cleaning with acetone. The chemical composition of annealed AISI D2 steel is $1.5 \mathrm{wt} \% \mathrm{C}, 11.5-12.5 \mathrm{wt} \% \mathrm{Cr}$, from 0.15 to $0.45 \mathrm{wt} \% \mathrm{Mn}, 0.6-0.9 \mathrm{wt} \% \mathrm{~W}$, and $\mathrm{Fe}$, which completes the chemical balance.

The coatings were developed from a salt bath comprised of molten borax $\left(\mathrm{Na}_{2} \mathrm{~B}_{4} \mathrm{O}_{7}\right)$, ferro-chromium (Fe-Cr), ferro-vanadium (Fe-V), and aluminum (Al), varying the chemical I composition (see Table 1). The aluminum was added to the salt bath as a reducing agent; i.e., it reduces boron oxide and rusts to prevent the added metal (chromium or vanadium) from rusting. It is thus available to combine with the carbon of the steel to form carbide. The TRD surface treatment was performed at $1020^{\circ} \mathrm{C}$ for $4 \mathrm{~h}$ with the preheating of the samples at $600{ }^{\circ} \mathrm{C}$.

Table 1. Chemical composition of the salt baths.

\begin{tabular}{ccccc}
\hline Sample & $\mathbf{W t} \% \mathbf{~ N a}_{\mathbf{2}} \mathbf{B}_{\mathbf{4}} \mathbf{O}_{\mathbf{7}}$ & $\mathbf{W t} \% \mathbf{F e}-\mathbf{C r}$ & $\mathbf{W t} \% \mathbf{F e}-\mathrm{V}$ & $\mathbf{W t} \% \mathbf{A l}$ \\
\hline M1 & 74 & 15 & 8 & 3 \\
M2 & 66 & 26 & 5 & 3 \\
M3 & 67 & 30 & - & 3 \\
M4 & 81 & - & 16 & 3 \\
\hline
\end{tabular}

The crystal structure of the coatings was determined by means of an analysis of the patterns of X-ray diffraction, obtained on a X-PertPro PANalytical device, working at $45 \mathrm{kV}$ and $40 \mathrm{~mA}$, emitting monochromatic radiation $\mathrm{Ka}$ of $\mathrm{Cu}(1.594 \AA)$ in the configuration $\theta-2 \theta$ in a range of $35^{\circ}$ to $85^{\circ}$, with a step of $0.02^{\circ}$. The chemical surface composition of the coating was determined through X-ray 
photoelectron spectroscopy (XPS). XPS spectra were recorded in a SPECS spectrometer in the constant pass energy mode at $50 \mathrm{eV}$, using $\mathrm{Mg} \mathrm{K} \alpha$ radiation as the excitation source. Sample cleaning was performed with $\mathrm{Ar}^{+}$ions of $3.5 \mathrm{keV}$ for $5 \mathrm{~min}$ in a preparation chamber (base pressure $2 \times 10^{-7} \mathrm{mbar}$ ) connected through a gate valve to the chamber. The calibration of the binding energy (BE) scale was checked using the $\mathrm{C} 1 \mathrm{~s}$ signal $(284.1 \mathrm{eV})$. X-ray spectroscopy (EDS) was carried out at a voltage of $20 \mathrm{kV}$ and collection time of $120 \mathrm{~s}$ in a FEI Quanta 200 scanning electron microscope (Thermo Fisher Scientific, Waltham, MA, USA). The measurement of the hardness of the coatings was performed with a CSM Berkovich nanoindentation instrument (Peseux, Switzerland) with a speed of approach to the sample of $2000 \mathrm{~nm} / \mathrm{min}$, a rate of application of the load of $10 \mathrm{mN} / \mathrm{min}$, and a maximum load of $30 \mathrm{mN}$, pausing for $15 \mathrm{~s}$ in the application of the load. The friction coefficient was evaluated through the pin-on-disk test using a CETR-UMC-2 tribometer (San Jose, CA, USA) with steel balls of $6 \mathrm{~mm}$ in diameter, coated with a layer of $\mathrm{Al}_{2} \mathrm{O}_{3}$ and with an applied load of $4 \mathrm{~N}$ at a speed of $50 \mathrm{~mm} / \mathrm{s}$ for $10 \mathrm{~min}$.

The wear track cross profile was measured for at least four points of the wear track with a Dektak 150 profilometer (Tucson, AZ, USA) in order to obtain an average of the wear-track width. After the test, the wear tracks were examined using a Bruker contour GT optical profilometer (Tucson, AZ, USA). The wear volume ( $\mathrm{Wv}$ ) of the films and the balls was calculated according to ASTM G99-17 [16]. The wear products were chemically analyzed using energy-dispersive X-ray spectroscopy (Thermo Fisher Scientific, Waltham, MA, USA) (EDS). The wearzrate (Ws) was calculated according to Archard's equation, Equation (1), where $F$ is the normal load $(\mathrm{N})$ and $L$ is sliding length $(\mathrm{mm})$. The wear rate is reported in $\mathrm{mm}^{3} / \mathrm{Nm}[16]$.

$$
W_{s}=\frac{W_{v}}{F \cdot L}
$$

The maximum contact pressure was 1.5 Pa with a contact radius of $1.5 \times 10^{-3} \mathrm{~m}$, assuming an elastic modulus of $380 \mathrm{GPa}$ and a Poisson ratio of 0.3 for $\mathrm{Al}_{2} \mathrm{O}_{3}$, and for the ternary carbide coating, an elastic modulus of $308 \mathrm{GPa}$ and a Poisson ratio of 0.24 . The contact radius and the contact pressure were useful for calculating the shear stress distribution along the $\mathrm{x}, \mathrm{y}$, and $\mathrm{z}$ directions for the two surfaces in contact, using the following Equations [17]:

$$
\begin{gathered}
\sigma_{x}=\sigma_{y}=-P_{0}(1+v)\left\{1-\left[\frac{z}{a}\right] \tan ^{-1}\left[\frac{a}{z}\right]\right\}+\frac{1}{2}\left[1+\frac{z^{2}}{a^{2}}\right]^{-1}, \\
\sigma_{z}=-P_{0}\left[1+\frac{z^{2}}{a^{2}}\right]^{-1}, \\
\tau_{\max }=\left|\frac{\sigma_{x}-\sigma_{z}}{2}\right|,
\end{gathered}
$$

where $\sigma_{x}, \sigma_{y}$ and $\sigma_{z}$ are the shear stress along the $\mathrm{x}, \mathrm{y}$, and $\mathrm{z}$ directions, respectively, $\mathrm{z}$ is the depth of the shear stress, and $\tau_{\max }$ is the maximum shear stress. Figure 1 shows the determined maximum shear stress and its distribution. The maximum shear stress was $239 \mathrm{MPa}$, located at a depth of $0.91 \mu \mathrm{m}$ below the coating surface.

The electrochemical behavior of the coatings was analyzed by means of potentiodynamic polarization and electrochemical impedance (EIS) tests. These measurements were performed on a Gamry 600 brand potentiostat instrument using an electrochemical cell with a volume of $100 \mathrm{~mL}$ in a solution of $3 \% \mathrm{NaCl}$ at $23{ }^{\circ} \mathrm{C}$. The analysis area was $0.196 \mathrm{~cm}^{2}$, using a bar of platinum and a calomel electrode as the auxiliary and reference electrodes, respectively. Polarization assays were performed with a scanning rate of $0.5 \mathrm{mV} / \mathrm{s}$, supplying a bias from -0.3 to $0.4 \mathrm{~V}$ with respect to the resting potential. EIS tests were conducted while varying the frequency from $0.01 \mathrm{KHz}$ to $100 \mathrm{MHz}$, applying a voltage of $10 \mathrm{mV}$. 


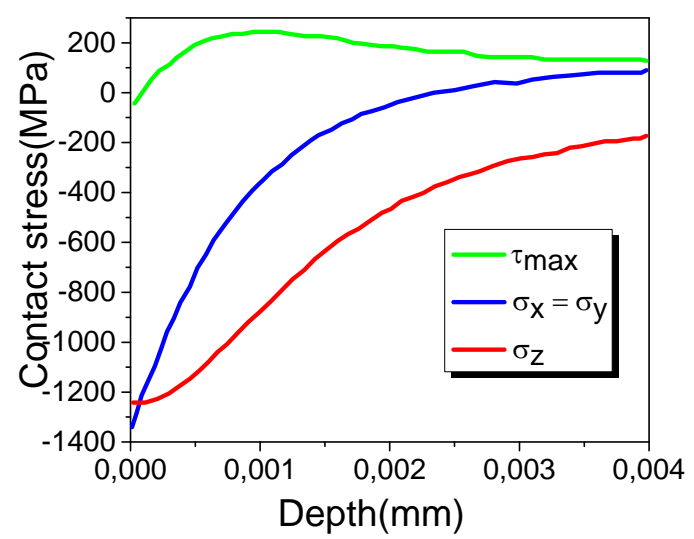

Figure 1. Shear stress distribution for the carbide coating of vanadium-chromium deposited on AISI D2 steel.

\section{Results}

Figure 2 shows the SEM micrographs of the cross section of three of the coatings produced on AISI D2. Using the measurement scale, it can be established that the coatings have the following thicknesses: M4: $12.4 \pm 0.2 \mu \mathrm{m}, \mathrm{M} 3: 13.1 \pm 0.1 \mu \mathrm{m}$, and M2: $12.7 \pm 0.5 \mu \mathrm{m}$. The M1 sample (not shown) had a thickness of $15.9 \pm 0.5 \mathrm{um}$. In general, the cross-section of the coatings is compact, since there were no pores and the deposited material was completely melted.

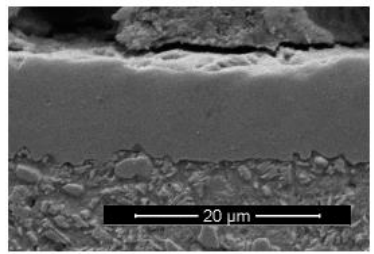

a) M4

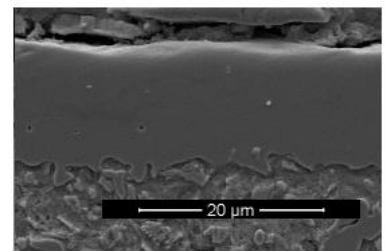

b) M3

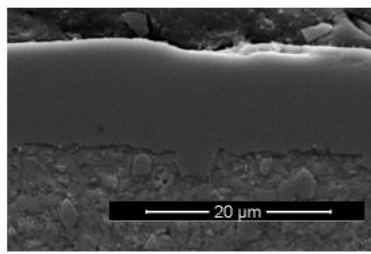

c) $\mathrm{M} 2$

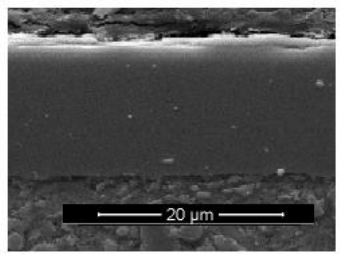

d) M1

Figure 2. SEM micrographs of the (a) M4; (b) M3; (c) M2; and (d) M1 samples.

Figure 3 shows the XRD patterns of each of the coatings (M1, M2, M3, and M4). The M4 sample exhibits the cubic $\mathrm{V}_{8} \mathrm{C}_{7}$ crystalline phase structure of the $\mathrm{NaCl}$ type [18]. This phase is reported on the PDF 00-025-1002 card, which assigned the highest intensities to planes (111) and (200). The coating grown from ferro-chrome (M3) has two crystalline phases: one for $\mathrm{Cr}_{23} \mathrm{C}_{6}$ belonging to the structure of $\mathrm{NaCl}$ (PDF 00-035-0783) with planes (420), (422), and (511) of high intensity, and the other for chromium carbide $\left(\mathrm{Cr}_{7} \mathrm{C}_{3}\right.$, PDF 00-036-1482), with an orthorhombic phase that highlights planes (150), (112), (151), and (060). Due the complex structure of the XRD patterns of the M1 and M2 samples, in Figure 4, the deconvolution of these patterns is shown in detail, where we see the presence of two for chromium carbide and one fors vanadium carbide. These results suggest that the samples with the greatest content of $\mathrm{Fe}-\mathrm{Cr}$ allow a chemical reaction between the carbon of the steel and the chromium of the bath. The presence of vanadium carbide in the M1 and M2 samples in the coatings can be explained by the greater thermodynamic stability in forming vanadium carbide, because the energy of formation of vanadium carbide $(-24 \mathrm{Kcal} / \mathrm{mol})$ [19] is less than that of chromium carbide $(-18 \mathrm{Kcal} / \mathrm{mol})$ [20]. 


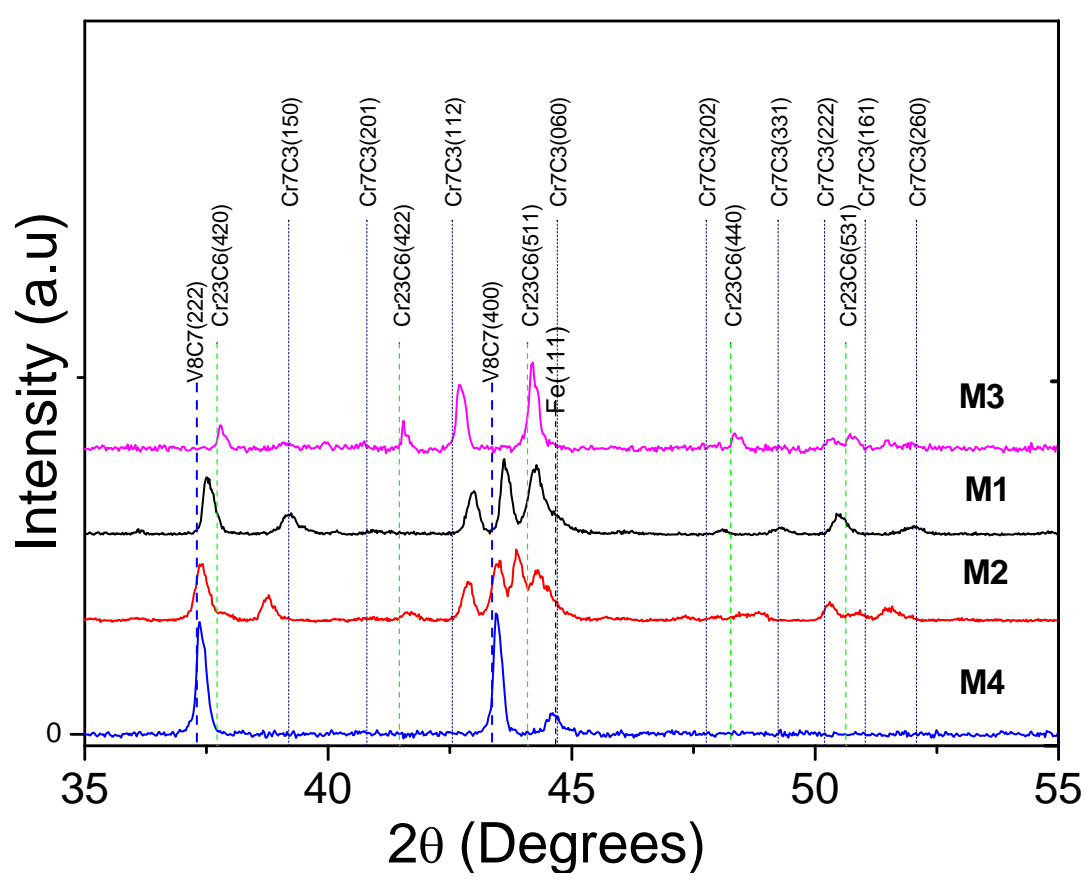

Figure 3. XRD patterns of different carbides.



Figure 4. Deconvolution of the XRD patterns for samples (a) M1 and (b) M2.

Figure 5 shows $\mathrm{K} \alpha$ and $\mathrm{K} \beta$ emission lines of the chromium (5.41 and $5.95 \mathrm{keV}$ ), vanadium (4.95 and $5.43 \mathrm{keV})$, aluminum (1.48 and $1.56 \mathrm{keV})$, and iron $(6.40$ and $7.06 \mathrm{keV})$ in the coatings. The $\mathrm{K} \alpha$ and $\mathrm{K} \beta$ lines are not detectable using the EDS technique because the energy of those lines is about $0.185 \mathrm{keV}$. Table 2 summarizes the content of each element in at $\%$. These results allow us to establish that the M1 sample, even though it was sinterized with a greater ferro-chromium content than ferro-vanadium, contains more $\mathrm{V}$ than $\mathrm{Cr}$ in the coating. This is because the formation energy of vanadium carbide is more negative than that of chromium carbide. In the M2 and M3 samples, the percentage of $\mathrm{Cr}$ increases, because the ferro-chromium increases from $26 \%$ to $30 \%$ wt. Finally, the M4 sample has a high content of vanadium because of the lack of ferro-chromium in the fabrication process. 

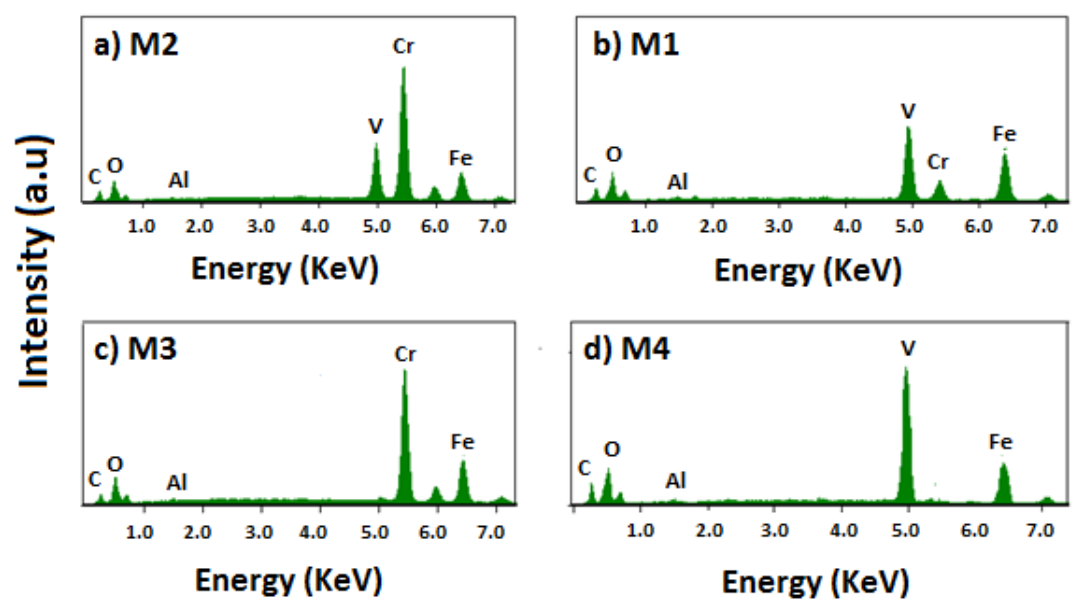

Figure 5. EDS spectra of the carbides grown on D2 steel. (a) M2; (b) M1; (c) M3; (d) M4.

Table 2. Chemical composition of the carbides grown on D2 steel evaluated via EDS.

\begin{tabular}{|c|c|c|c|c|c|c|}
\hline & $\mathrm{V}(\mathrm{Wt} \%)$ & $\mathrm{Cr}(\mathrm{Wt} \%)$ & $\mathrm{C}(\mathrm{Wt} \%)$ & $\mathrm{Fe}(\mathrm{Wt} \%)$ & $\mathrm{Al}(\mathrm{Wt} \%)$ & $\mathrm{O}(\mathrm{Wt} \%)$ \\
\hline M1 & 63.88 & 4.14 & 4.78 & 21.26 & 1.95 & 3.97 \\
\hline M2 & 9.46 & 54.04 & 3.09 & 29.73 & 1.88 & 1.90 \\
\hline M3 & - & 53.48 & 2.91 & 31.77 & 1.60 & 10.24 \\
\hline M4 & 66.04 & - & 10.08 & 6.84 & - & 17.04 \\
\hline
\end{tabular}

Figure 6 shows XPS spectra for the Cr carbide coatings of the M1-V sample deposited on tool steel. Figure 6a shows the extended XPS spectrum. In this spectrum, binding energies can be identified corresponding to vanadium, chromium, oxygen, carbon, and iron on the coating's surface. Figure $6 \mathrm{~b}$ shows the high-resolution XPS spectrum of $\mathrm{C} 1$ s. Within the spectrum, four contributions can be identified. The first is centered on $284.4 \mathrm{eV}$, which corresponds to the aliphatic carbon found on the coating's surface; the second is centered on $285.6 \mathrm{eV}$, which corresponds to the binding energy of $\mathrm{C}$ in the vanadium carbide; and the last two contributions are focused on 286.5 and $287.4 \mathrm{eV}$, corresponding to the binding energy of $C$ in the chromium carbide [21].

In Figure $6 c$, the $2 p$ peak of $\mathrm{Cr}$ is exhibited, formed by the contributions of two peaks centered at 576.12 and $574.4 \mathrm{eV}$. These energies correspond to chromium oxide $\left(\mathrm{Cr}_{2} \mathrm{O}_{3}\right)$ and chromium carbide $\left(\mathrm{Cr}_{3} \mathrm{C}_{2}\right)$. Figure $6 \mathrm{~d}$ shows the V2p and O1s peaks, which are composed of two contributions: V $2 \mathrm{p}$ exhibits binding energies centered at 512.6 and $514.2 \mathrm{eV}$. These energies correspond to the V-C bonding, and the other peak corresponds to vanadium oxide. The O1s peak has four contributions: (i) one centered at $530.1 \mathrm{eV}$, corresponding to $\mathrm{Cr}_{2} \mathrm{O}_{3}$ [22]; (ii) one centered at $531.4 \mathrm{eV}$, which is the energy of an $\mathrm{OH}$ group; (iii) one centered at $532 \mathrm{eV}$, which is the energy corresponding to the water absorbed by the coating (when it is exposed to the atmosphere); and iv) one centered at $533 \mathrm{eV}$, which is the energy of the oxygen absorbed into the vanadium carbide [23].

The hardness values obtained for the carbide coatings are shown in Table 3. The lowest hardness value for M3 is obtained in the sample corresponding to chromium carbide (14.7 GPa), and for the M4 sample, vanadium carbide values above $20 \mathrm{GPa}$ were recorded, which are consistent with other studies [24,25]. Overall, a significant increase in hardness for the chromium-vanadium systems (M1 and M2) was not observed, possibly because there is no substantial atomic substitution between the crystal lattices of the materials that form the coatings. Table 3 also shows the wear rate of the carbide coatings. These values show evidence that all the coatings have higher wear resistance than the substrate. Furthermore, the M3 sample exhibits the lowest wear resistance, possibly due to the low degree of hardness. 

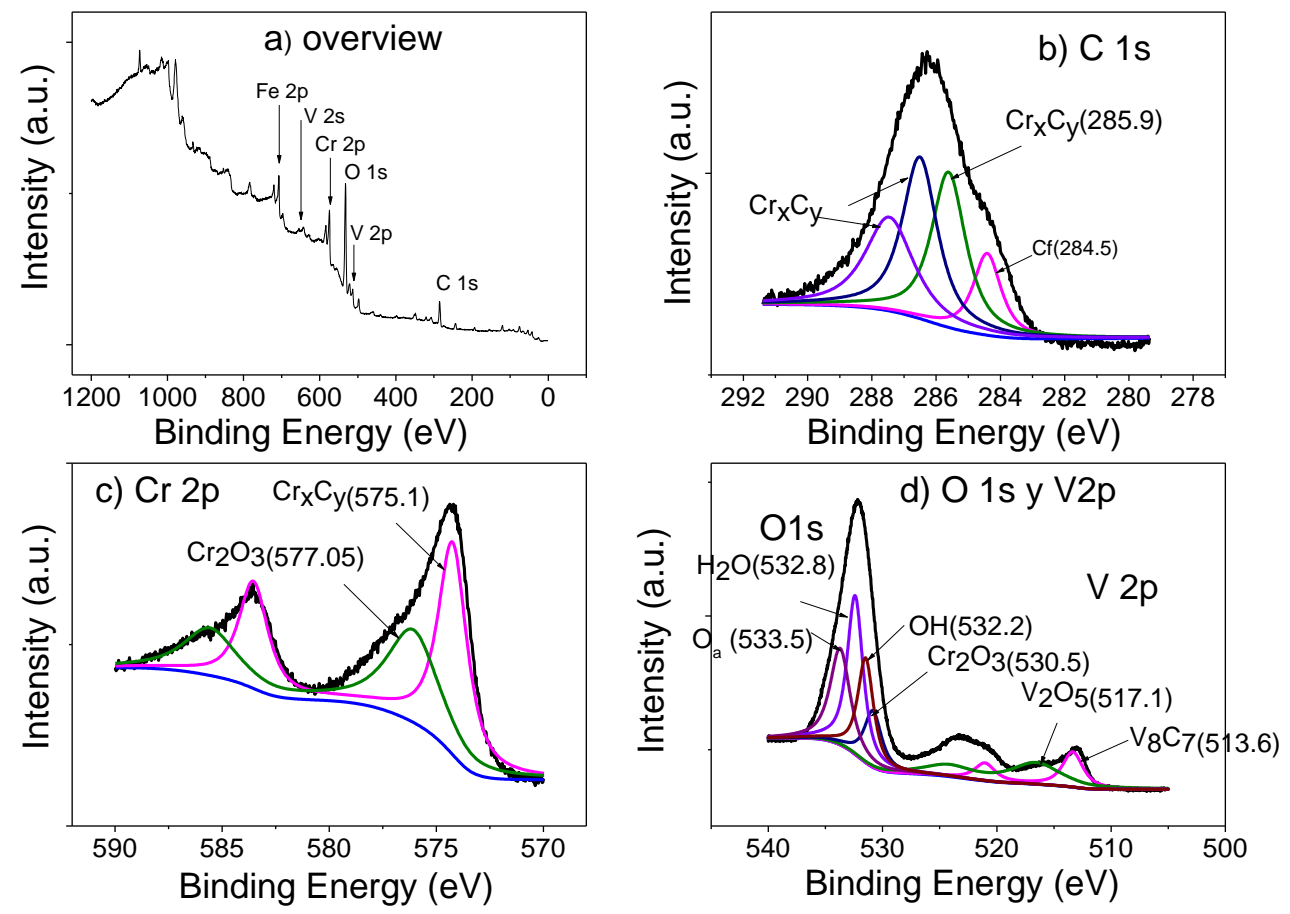

Figure 6. XPS spectra of the coatings deposited on the M2 sample. (a) survey spectra; (b) high resolution of $\mathrm{C} 1 s$; (c) high resolution of $\mathrm{Cr} 2 p$; (d) high resolution of $\mathrm{O} 1 s$.

Table 3. Hardness of the coatings deposited on AISI D2.

\begin{tabular}{ccc}
\hline Sample & Hardness (Gpa) & Rate Wear \\
\hline AISI D2 & $6.45 \pm 0.28$ & $324 \times 10^{-6}$ \\
M1 & $23.3 \pm 0.91$ & $26 \times 10^{-6}$ \\
M2 & $25.1 \pm 1.1$ & $23 \times 10^{-6}$ \\
M3 & $14,7 \pm 0.65$ & $47 \times 10^{-6}$ \\
M4 & $24.82 \pm 0.69$ & $26 \times 10^{-6}$ \\
\hline
\end{tabular}

Figure 7 shows the curves of the friction coefficient for each of the carbides deposited on AISI D2. From the graph, it can be established that the coefficient of friction (COF) of the grown carbides is between 0.3 and 0.4 , while for the substrate it is greater than 0.6 . These values agree with results obtained in other studies [26]. The decrease in the coefficient of friction of the coatings compared with the substrate could be explained by considering that there is free carbon on the surface, which probably acts as a lubricant when the ball-on-disk test is performed.

Figure 8 shows the scar wear for the M1 and M2 samples. The figure shows parallel lines or channels, characteristic of adhesive wear. According to Adachi and Hutchings, this situation is known as grooving wear, or the abrasion of two bodies [27]. These slots arise from the cutting action of abrasive microparticles that are fundamentally embedded in the ball with which the test is conducted. The microparticles were possibly produced by the mechanisms of the contact fatigue and the plastic deformation that are generated during the contact of the tribological pair. These types of wear can be combined with an oxidation wear mechanism promoted by the formation of oxides due to the increase in temperature and the reaction of elements such as chromium and vanadium with the oxygen in the environment, possibly forming a film that prevents the continuous removal of material. 


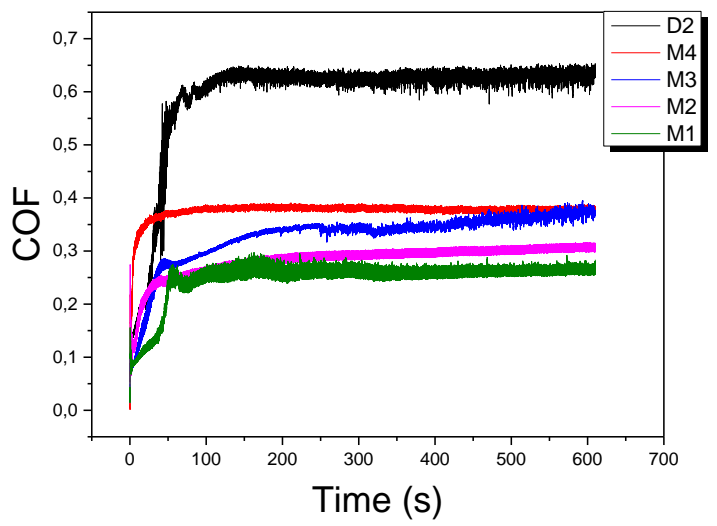

Figure 7. Coefficient of friction versus time for the carbides deposited on AISI D2.

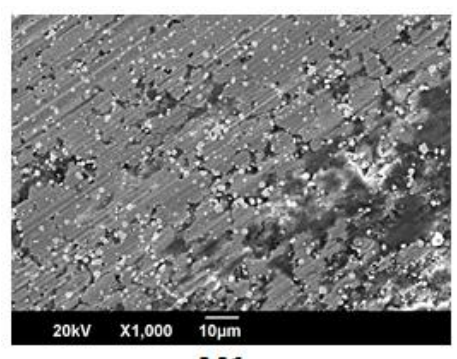

M1

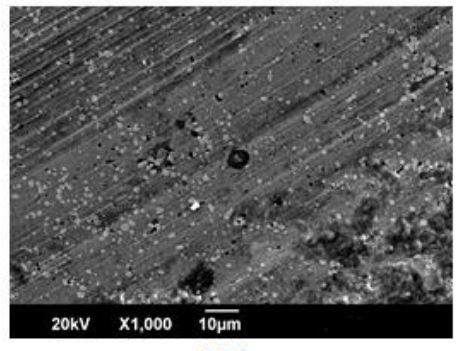

M3

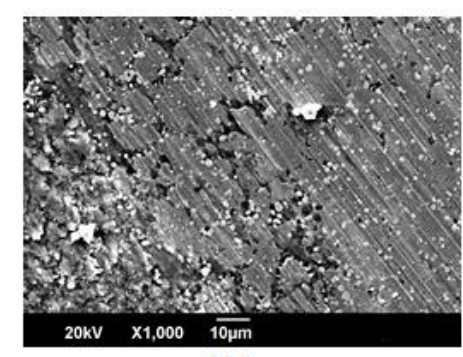

M2



M4

Figure 8. SEM micrographs of the wear tracks for the (a) M1; (b) M2; (c) M3; and (d) M4 samples.

To determine the corrosion rate of the coating-substrate system, the potential vs. current curves, called potentiodynamic polarization and Tafel polarization, can be used. Figure 9 shows the curves obtained for uncoated AISI D2 steel and for the coatings. Table 4 summarizes the parameters obtained through this measurement. From the values in the table, it can be established that the coated steels exhibit increased corrosion resistance, since the corrosion current Icorr decreases by an order of magnitude with respect to the Icorr values for the AISI D2. Additionally, the results show that the coatings that grow in a salt bath with the highest concentration of vanadium exhibit lower corrosion resistance, while the coatings with chromium contents exhibit the best protection against corrosion These results can be explained by considering the XPS analysis, which showed the formation of two types of oxide in the coating: chromium oxide $\left(\mathrm{Cr}_{2} \mathrm{O}_{3}\right)$ and vanadium oxide $\left(\mathrm{V}_{2} \mathrm{O}_{5}\right)$. Chromium oxide has a high degree of chemical stability and is used in industry as a protective material against degradation in layers or thin films [28,29], and vanadium oxide is chemically unstable and therefore does not have the ability to serve as a protective layer [30,31]. 


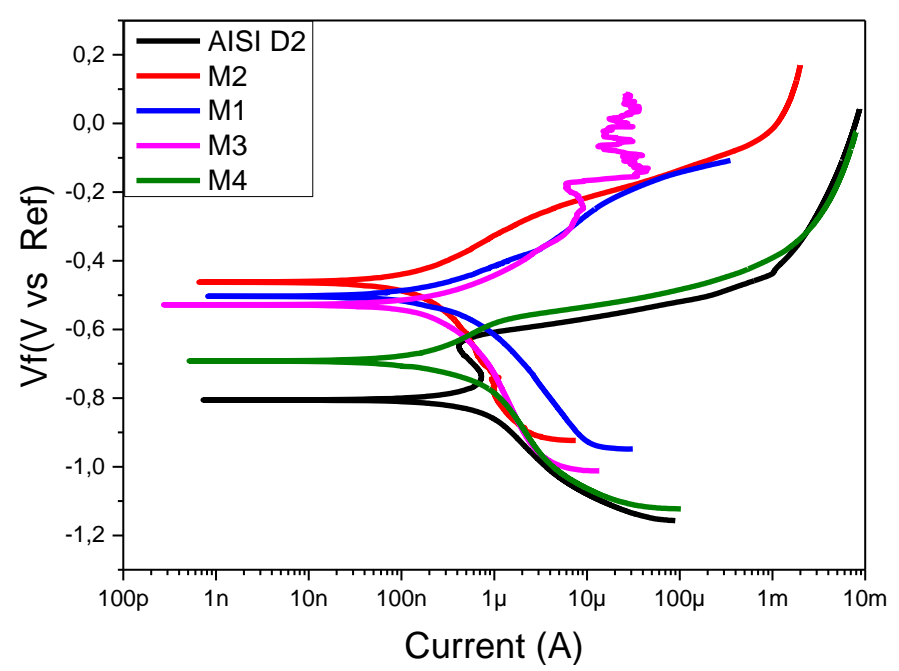

Figure 9. Linear polarization curves for carbide coatings.

Table 4. Parameters obtained from the linear polarization curves for each of the coatings: current corrosion (Icor), corrosion potential (Ecor), and the anodic $(\beta a)$ and cathodic $(\beta c)$ Tafel slopes.

\begin{tabular}{ccccccc}
\hline Sample & Icorr (A) & Error & Ecorr $(\mathbf{m V})$ & Error & Ba $(\mathbf{V})$ & Bc $(\mathbf{V})$ \\
\hline M1 & $1.28 \times 10^{-7}$ & $2.68 \times 10^{-8}$ & -489.3 & 2.1 & 0.18 & 0.49 \\
M2 & $1.63 \times 10^{-7}$ & $1.81 \times 10^{-8}$ & -544.7 & 1.5 & 0.19 & 0.36 \\
M3 & $1.22 \times 10^{-7}$ & $2.98 \times 10^{-8}$ & 458.6 & 3.5 & 0.17 & 0.5297 \\
M4 & $6.66 \times 10^{-7}$ & $9.50 \times 10^{-8}$ & -692.7 & 5.2 & 0.29 & 0.438 \\
AISI D2 & $1.19 \times 10^{-6}$ & $1.07 \times 10^{-7}$ & -807 & 1.2 & 0.362 & 0.251 \\
\hline
\end{tabular}

Figure 10 shows the electrochemical impedance spectroscopy (EIS) spectra obtained for the steel and the carbides after 7 days of corrosion treatment in a solution of $3 \% \mathrm{NaCl}$. The equivalent circuits (EC) proposed for the fit of the experimental spectra are shown in Figure 11. The fit between the theoretical and experimental spectra was performed with Gamry Echem Analyist software, version 7. The EC corresponding to AISI D2 (Figure 11a) has a resistance, Rsol, which is the solution resistance, connected in series with two parallel elements: a constant phase element (CPE) with an exponent $n$, in which a value of 1 indicates that that element of the proposed circuit is completely capacitive, and a value of 0 indicates that that circuit element is resistive. Values between 0 and 1 indicate a capacitive and resistive behavior. Rpol is the polarization resistance, which is the resistance to the passage of charge through the substrate-electrolyte interface. For the coated steel (Figure 11b), the proposed circuit represents a coating material with pores. The EC has an Rsol that represents the resistance of the electrolytic solution, a constant phase element $\mathrm{CPE}-\mathrm{c}$ with its exponent $\mathrm{m}$ that represents the coating-solution interface, and Rpor, which represents the resistance to charge transfer through the pores. Additionally, a second constant phase CPE-s is included, with its exponent $\mathrm{n}$ along with the corrosion resistance Rcor describing the electrochemical behavior and the resistance to charge transfer at the coating-substrate interface.

Bode plots show a polarization resistance at $0.01 \mathrm{~Hz}$ in the range of $5 \mathrm{k} \Omega$ for the AISI D2 substrate (Figure 10), while for the coatings, the impedance values are about $10 \mathrm{k} \Omega$ at the same frequency. In general, the impedance decreases with the exposure time for all cases, which could be due to the increase in porosity over time, which allows the electrolyte to penetrate and reach the coating-substrate interface. Additionally, the figure that shows the behavior of the phase as a function of the frequency shows two relaxation times for the coatings. This is evident in the coating submerged for 7 days (blue curve triangles). These relaxation times are given by [32] 


$$
\tau_{c}=R_{\text {por }} C_{c} \quad \tau_{c o r}=R_{c o r} C_{s}
$$

where $C_{c}$ is the capacitance of coatings and $C_{S}$ is the capacitance of the substrate-coating interface.

The relaxation time at high frequencies represents the dielectric coating performance $\left(C_{c}\right.$, Rpor), and the relaxation time at low frequencies represents the properties of the substrate/coating interface $\left(C_{s}\right.$, Rcor) [33]. Bode diagrams of the M4 sample do not show good corrosion resistance, since the sample has a layer of vanadium oxide on the surface, which has little chemical stability (Figure 9b), while the M2 sample exhibits high corrosion resistance due to the presence of a surface layer of chromium oxide, which has excellent chemical stability and acts as a protective coating. The values of the parameters obtained after the fit of the proposed equivalent circuits are summarized in Table 5 for the coatings produced, after exposure times of $168 \mathrm{~h}$. The result shows that Rpor and Rcor are lower for the M4 sample, indicating low corrosion resistance for this coating. This could be explained by the formation of only vanadium oxide in the coating during its production, as seen in the XPS spectra, whereas the coatings with high chromium content have higher values of Rcor and Rpor, which could be explained by the presence of $\mathrm{Cr}_{23} \mathrm{C}_{6}$ and $\mathrm{Cr}_{7} \mathrm{C}_{3}$ along with the formation of the stable oxide $\mathrm{Cr}_{2} \mathrm{O}_{3}$, creating a passive layer on the coating that protects the substrate from electrolyte penetration.
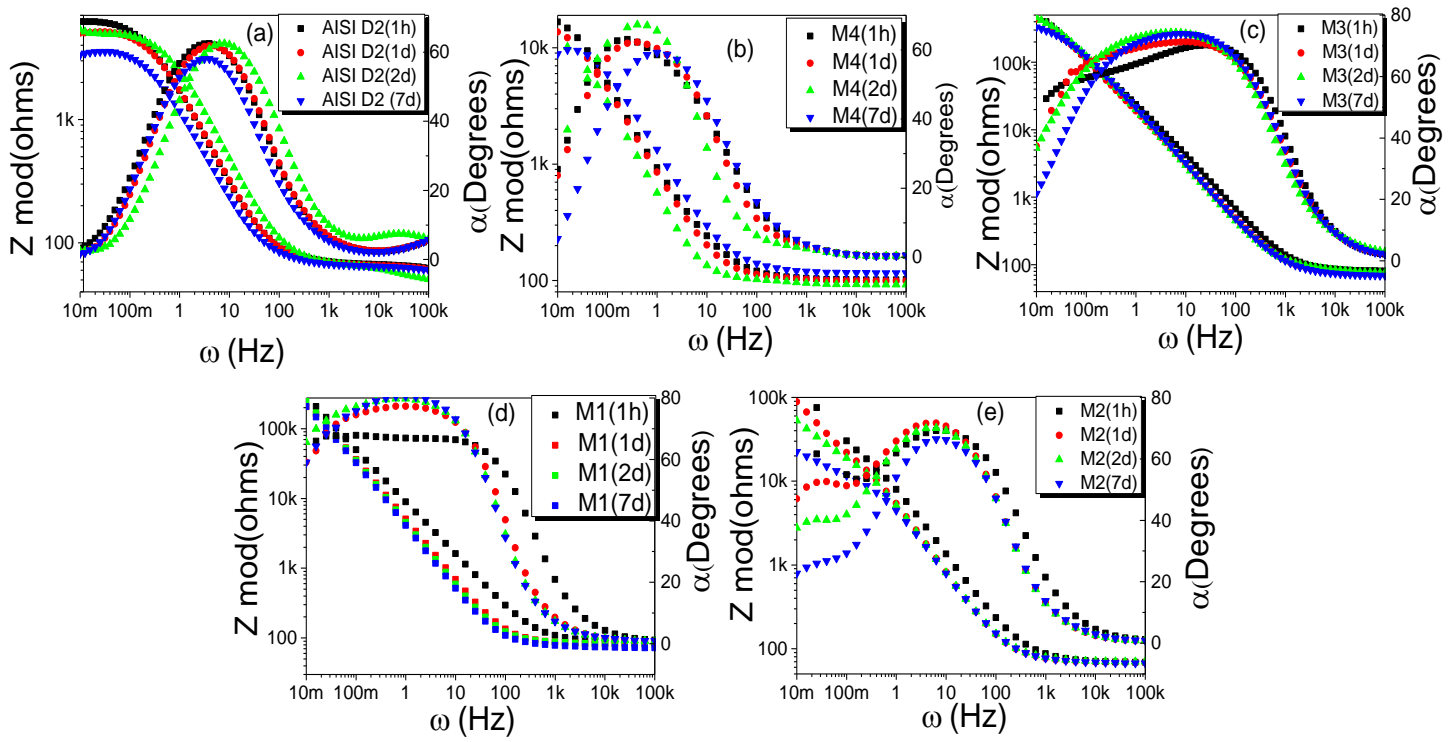

Figure 10. Bode plots for carbide coatings. (a) substrate; (b) M4; (c) M3; (d) M1; (e) M2.

(a)



(b)

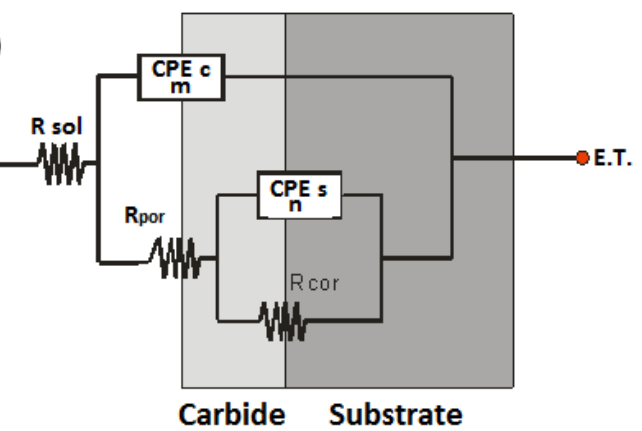

Figure 11. Equivalent circuits for electrochemical impedance spectroscopy (EIS) tests. (a) substrate (b) coating. 
Table 5. Values of the parameters obtained after the fit of the proposed equivalent circuits to the coatings produced, after exposure times of $168 \mathrm{~h}$. CPE: constant phase element.

\begin{tabular}{cccccccc}
\hline Sample & Rsol $(\Omega)$ & Rcor $(\Omega)$ & Rpor $(\Omega)$ & CPE-c & m & CPE-s & n \\
\hline M1 & 74.4 & 2176 & 3087 & $7.1 \times 10^{-10}$ & 0.5 & $1.1 \times 10^{-3}$ & 0.80 \\
M2 & 68.2 & 11,160 & 14,010 & $1.8 \times 10^{-10}$ & 0.76 & $1.95 \times 10^{-5}$ & 0.83 \\
M3 & 68.4 & 21,710 & 12,730 & $4.02 \times 10^{-10}$ & 0.76 & $4.27 \times 10^{-5}$ & 0.82 \\
M4 & 103 & 11,000 & 90 & $2.13 \times 10^{-6}$ & 0.77 & $4.17 \times 10^{-5}$ & 0.63 \\
\hline
\end{tabular}

\section{Conclusions}

Carbides of vanadium, chromium, and chromium-vanadium were grown using the TRD technique on AISI D2 tool steels. The coatings exhibit a good uniformity of thickness values, between 12 and 15 microns, and a value of hardness greater than that of the substrate.

Moreover, potentiodynamic polarization curves show better performance as a protective coating than those grown with greater chromium content in the salt bath treatment. The EIS spectra confirm the nature of the ceramic carbide produced, which improves the electrochemical performance of the coatings compared with uncoated steel.

The wear tests for samples M1 and M2 show the presence of parallel channels, characteristic of adhesive wear. This morphology is the result of wear or abrasion between two bodies. The friction coefficients are lower for the carbides than for uncoated steel, mainly due to the presence of a hard coating on the surface.

Author Contributions: F.E.C., J.E.A. and J.J.O. conceived and designed the experiments; F.E.C. performed the experiments; F.E.C., J.E.A. and J.J.O. wrote the paper.

Funding: The authors are grateful for the financial support of Colciencias through the project with code 1101-521-28337 and contract 338-2011.

Conflicts of Interest: The authors declare no conflict of interest.

\section{References}

1. He, J.L.; Lin, Y.H.; Chen, K.C. Wear performance of CAP-titanium nitride-coated high-speed steel in different dry sliding conditions. Wear 1997, 208, 36-41. [CrossRef]

2. Su, Y.L.; Kao, W.H. Optimum multilayer TiN-TiCN coatings for wear resistance and actual application. Wear 1998, 223, 119-130. [CrossRef]

3. Oliveira, C.K.N.; Muñoz Riofano, R.M.; Castiletti, L.C. Micro-abrasive wear test of niobium carbide layers produced on AISI H13 y M2. Surf. Coat. Technol. 2006, 200, 5140-5144. [CrossRef]

4. Arai, T.; Harper, S. Thermoreactive Deposition/Diffusion Process; ASM Handbook Volume 4; ASM International: Materials Park, OH, USA, 1991; p. 448.

5. Oliveira, C.K.N.; Muñoz Riofano, R.M.; Castiletti, L.C. Evaluation of hard coatings obtained on AISI D2 steel by thermo-reactive deposition treatment. Surf. Coat. Technol. 2006, 201, 1880-1885. [CrossRef]

6. Arai, T.; Fujita, H.; Sugimoto, Y.; Ohta, Y. Diffusion carbide coatings formed in molten borax systems. J. Mater. Eng. 1987, 9, 183. [CrossRef]

7. Child, H.C.; Plumb, S.A.; McDermott, J.J. Proc. Heat Treatment'84; The Metals Society: London, UK, 1984; Volume 310, p. 5.1.

8. Sinha, A.K. Boriding (Boronizing); ASM Handbook Volume 4; ASM International: Materials Park, OH, USA, 1991; p. 437.

9. Sen, S.; Ozbek, S.I.; Bindal, C. Mechanical behavior of borides formed on borided cold work tool steel. Surf. Coat. Technol. 2001, 135, 173-177. [CrossRef]

10. Sen, U. Kinetics of niobium carbide coating produced on AISI 1040 steel by thermo-reactive deposition technique. Mater. Chem. Phys. 2004, 86, 189-194. [CrossRef] 
11. Sen, S. A study on kinetics of CrxC-coated high-chromium steel by thermo-reactive diffusion technique. Vacuum 2005, 79, 63-70. [CrossRef]

12. Saduman, S.; Ugur, S.; Bindal, C. The growth kinetics of borides formed on boronized AISI 4140 steel. Vacuum 2005, 77, 195-202.

13. Frangini, S.; Masci, A.; Di Bartolomeo, D. Cr C -based cermet coating deposited on stainless steel by electro spark process: structural characteristics and corrosion behavior. Surf. Coat. Technol. 2002, 149, 279-286. [CrossRef]

14. Aguzzoli, C.; Figueroa, C.A.; de Souza, F.S.; Spinelli, A.; Baumvol, I.J.R. Corrosion and nanomechanical properties of vanadium carbide thin film coatings of tool steel. Surf. Coat. Technol. 2012, 206, 2725-2731. [CrossRef]

15. Viswanathan, S.; Haitong, Z.; Daniel, L.; Zongtao, Z.; Gilbert, L. Electrochemical investigation of chromium nanocarbide coated Ti-6Al-4V and Co-Cr-Mo alloy substrate. Electrochim. Acta 2012, 59, 387-397.

16. ASTM G99-17. Standard Test Method for Wear Testing with a Pin-on-Disk Apparatus; ASTM International: West Conshohocken, PA, USA, 2017.

17. Castillejo, F.E.; Marulanda, D.M.; Olaya, J.J.; Alfonso, J.E. Wear and corrosion resistance of niobiumchromium carbide coatings on AISI D2 produced through TRD. Surf. Coat. Technol. 2014, 254, 104-111. [CrossRef]

18. Villars, P.; Calvert, L.D. Pearson's Handbook of Crystallographic Phases; ASTM International: West Conshohocken, PA, USA, 1991; ISBN 0-87170-418-8.

19. Worrell, W.L.; Chipman, J. The free energies of formation of the vanadium, niobium, and tantalum carbides. J. Phys. Chem 1964, 68, 860-866. [CrossRef]

20. Arai, T.N.; Komatsu, N.; Mizutani, M. Diffusion layers of steel surfaces Immersed in fused borax baths containing various kinds of aditives. J. Jpn. Inst. Met. 1975, 39, 247-255. [CrossRef]

21. Zhao, Z.; Zheng, H.; Wang, Y.; Mao, S.; Niu, J.; Chen, Y.; Shang, M. Synthesis of chromium carbide $\left(\mathrm{Cr}_{3} \mathrm{C}_{2}\right)$ nanopowders by the carbonization of the precursor. Int. J. Refract. Met. Hard Mater. 2011, 29, 614-617. [CrossRef]

22. Sa1d Agouram, Franz Bodart, Guy Terwagne. J. Electron Spectrosc. Relat. Phenom. 2004, 134, 173-181.

23. Choi, J.-G. The surface properties of vanadium compounds by X-ray photoelectron spectroscopy. Appl. Surf. Sci. 1999, 148, 64-72. [CrossRef]

24. Castillejo, F.; Arroyo, J.M.; Olaya, J.J. Nb-Cr complex carbide coatings on AISI D2 steel produced by the TRD process. J. Braz. Soc. Mech. Sci. Eng. 2015, 37, 87-92. [CrossRef]

25. Fan, X.S.; Yang, Z.G.; Zhang, C.; Zhang, Y.D.; Che, H.Q. Evaluation of vanadium carbide coatings on AISI H13 obtained by thermo-reactive deposition/diffusion technique. Surf. Coat. Technol. 2010, 205, 641-646. [CrossRef]

26. Bourithis, L.; Papadimitriou, G.D.; Sideris, J. Comparison of wear properties of tool steels AISI D2 and O1 with the same hardness. Tribol. Int. 2006, 39, 479-489. [CrossRef]

27. Adachi, K.; Hutchings, I.M. Wear-mode mapping for the micro-scale abrasion test. Wear 2003, 255, $23-29$. [CrossRef]

28. Liu, H.; Tao, J.; Xu, J.; Chen, Z.; Liu, Q.G.; Tao, J.; Xu, J.; Chen, Z.; Gao, Q. Corrosion and tribological behaviors of chromium oxide coatings prepared by the glow-discharge plasma technique. Surf. Coat. Technol. 2009, 204, 28-36. [CrossRef]

29. Toma, D.; Brandl, W.; Marginean, G. Wear and corrosion behavior of thermally sprayed cermet coatings. Surf. Coat. Technol. 2001, 138, 149-158. [CrossRef]

30. Al-Kharafi, F.M.; Badawy, W.A. Electrochemical behavior of vanadium in aqueous solutions of different $\mathrm{pH}$. Electrochem. Acta 1997, 42, 579-586. [CrossRef]

31. Zhou, X.; Wu, G.; Gao, G.; Cui, C.; Yang, H.; Shen, J.; Zhou, B.; Zhang, Z. The synthesis, characterization and electrochemical properties of Multi-wall carbon Nanotube-induced vanadium oxide nanosheet composite as a novel cathode material for lithium ion batteries. Electrochim. Acta 2012, 74, 32-38. [CrossRef] 
32. Liu, C.; Bi, Q.; Leyland, A.; Matthews, A. An electrochemical impedance spectroscopy study of the corrosion behaviour of PVD coated steels in $0.5 \mathrm{~N} \mathrm{NaCl}$ aqueous solution: Part I. Establishment of equivalent circuits for EIS data modelling. Corros. Sci. 2003, 45, 1243-1256. [CrossRef]

33. Liu, C.; Bi, Q.; Leyland, A.; Matthews, A. An electrochemical impedance spectroscopy study of the corrosion behavior of PVD coated steels in $0.5 \mathrm{~N} \mathrm{NaCl}$ aqueous solution: Part II. EIS interpretation of corrosion behavior. Corros. Sci. 2003, 45, 1257-1273. [CrossRef]

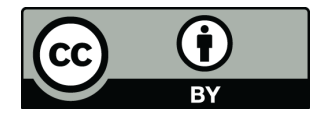

(C) 2019 by the authors. Licensee MDPI, Basel, Switzerland. This article is an open access article distributed under the terms and conditions of the Creative Commons Attribution (CC BY) license (http://creativecommons.org/licenses/by/4.0/). 